\title{
Research on the Status Quo and Countermeasures of Information Disclosure of Internal Control Defects in Listed Companies
}

\author{
Qiuhong Liu \\ School of Economics and Management, Panzhihua University, Panzhihua, Sichuan 617000, China
}

Keywords: Listed company; Internal control; Disclosure of defects

Abstract: Since the reform and opening-up, China's economy has achieved tremendous development. At the same time, with the continuous deepening of the market economic system, the number of listed companies has gradually increased. In recent years, Hong Baoli's "fake bill gates" and Everbright's "Oolong refers to incidents" and other cases indicate that there are serious flaws in the internal control of listed companies, which have an important impact on the operation and development of enterprises to serve the public. The benefits cause a certain degree of damage. It can be seen that the smooth development of the internal control of the enterprise has important significance for the development of the enterprise. This paper analyzes and studies the status quo of internal control defect information disclosure of listed companies, and proposes scientific and effective countermeasures, aiming at improving the internal control level of enterprises and promoting the sustainable development of enterprises, and hopes to provide reference for future research.

\section{Introduction}

As an important part of the continuous improvement of the internal control operation mechanism, internal control information disclosure can timely resist the risks from different aspects of the enterprise, and establish a solid "firewall" for the enterprise through organic integration with internal control. The management of the enterprise shall assume the responsibility and obligation of internal control, and carry out reasonable internal control audit and ensure its operational effect, realize the symmetry of the information of the company's senior management department with information users, creditors and investors, and report in the form of report Disclosure [1]. At present, there are clear requirements for the disclosure format and content, but the specifications of the scope, standards and quality of related content still need to be continuously improved.

\section{Status of disclosure of internal control defects in listed companies}

In recent years, the disclosure of internal control defects of listed companies has been widely concerned by the public. At the same time, the disclosure of internal control defects of listed companies directly determines the success or failure of the development of enterprises and the interests of all stakeholders. It is the internal control self-assessment report. important content. 
3117 listed companies listed on the A-shares of Shanghai and Shenzhen Stock Exchanges and disclosed the 2016 annual report before April 30, 2017 were selected as the research objects, and their internal control disclosures were analyzed. This report is a phased research result of the National Natural Science Foundation's key project "Investigation on the Effectiveness of Internal Control of Enterprises Based on China's Situation”. 2,864 listed companies disclosed the annual internal control evaluation report, accounting for $91.88 \%$ of the number of A-share listed companies that disclosed the annual report. Among them, the internal control system was identified as 2834 and 30 listed companies with overall effectiveness and non-overall effectiveness, accounting for 90.92\% and $0.97 \%$ respectively. 512 listed companies disclosed their internal control deficiencies, accounting for $17.89 \%$ of the number of internal control evaluation reports. A total of 512 listed companies disclosed 4,447 internal control defects. Among them, 61 major defects, accounting for 1.36\%; 54 important defects, accounting for 1.20\%; general defects 4332, accounting for $97.41 \%$. Major and important defects all disclosed specific defects, and 1121 of the general defects disclosed specific defects. It can be seen that most listed companies in China have gradually recognized the importance of internal control information disclosure, responded positively to the requirements put forward by regulatory agencies, and formulated and implemented a series of measures to carry out internal control information. Disclosure work.

In the 21st document, China has standardized the content and format of internal control defect information disclosure. The content of this article provides clear guidance for the disclosure of internal control defects information in listed companies in China. The following specific aspects are specified: First, listed companies must formulate specific internal control defect information standards from both financial and non-financial aspects. The size and characteristics of the company will have certain impact on the internal control defect information standards; When establishing standards, it is necessary to elaborate and divide from two aspects: qualitative and quantitative. Third, the company must correctly recognize that only the assurance of the criteria can be achieved in order to achieve the company's established financial goals. Fourth, the company should be based on specific circumstances. Adjust and changes to the certification standards, because the company's general defects or important defects will have an important impact on all aspects of the company [2]. As a result, more and more listed companies in China have begun to independently prepare internal control information disclosure evaluation reports.

\section{The existence of problems in the disclosure of internal control defects of listed companies}

\subsection{The certification standard is not perfect}

Since China has not effectively classified the identification standards for information disclosure of internal control defects of listed companies, it only starts from the perspective of financial reports and non-financial reports, while financial reports and non-financial reports are major defects in internal control. In the "Guidelines for Internal Control Support", the defect information is divided into three levels, which are major defects, important defects and general defects, but this classification gradually reflects its imperfection in specific practice, resulting in the company's the adverse effects caused by imperfections cannot be properly mastered. If the company has been in such a state of unclear concept, the problem of its established certification standards can easily cause some important degree of controllable internal control defects cannot be effectively paid attention. At the same time, the internal control audit report issued by the accounting firm may also have the problem of not being able to fully report the defects, but only report the defects that may appear on the surface [4]. In addition, it is also very subjective in terms of what kind of events are included in the scope of major defects. Due to the imperfect standard of identification, it will directly affect the smooth progress of information disclosure of internal control defects. 


\subsection{Lack of scientific and effective supervision mechanism}

Some companies will disclose some unimportant defects to the regulatory authorities when they are inspected by the regulatory authorities, or if some major defects are disclosed, the rectification of these defects has been completed, and the impact on the company is minimal. of. If the information disclosed is a defect that investors do not care about, it will lose the influence and significance of the investor's decision-making behavior. It can be seen that there is no scientific and effective supervision mechanism in the process of information disclosure of internal control defects of listed companies. If we want to better improve the effect of disclosure of internal control defects, we need to establish and improve the corresponding supervision mechanism to make internal control defects. Information disclosure is enforced and the desired effect is achieved [5].

\subsection{The implementation of the rectification plan is not in place}

In the process of developing internal control defect information disclosure, listed companies also need to establish corresponding defect adjustment plans, which are to ensure that the problems existing in the company's operation process are comprehensively solved, operational efficiency is improved, and the interests of investors are effectively safeguarded. However, some listed companies lack a comprehensive understanding of internal control defect information disclosure, so the defect rectification plan formulated does not consider the problem from the perspective of the company's overall nature, resulting in the expected goal cannot be better achieved. If the disclosure of internal control defect information is carried out smoothly, it will inevitably promote the sustainable development of the company. It can be seen that the disclosure of internal control defect information is of great significance to the development of the company.

\subsection{Large human selectivity}

At present, many listed companies in China have already disclosed internal control defect information and achieved remarkable results, which have effectively reduced the company's risks and losses. At present, most enterprises in China are more inclined to disclose some general defects in internal control defect information, or to reduce the disclosure of major defects and important defects, and these defects have little impact on enterprises, and their disclosure is only Generally speaking, there are defects and improvements, there is no specific explanation for the improvement of the content, and the proposed disclosure improvement strategy cannot be improved [6]. In addition, few companies will rectify the disclosure of internal control defects in the previous year and terminate the improvement process without authorization, which is not conducive to the long-term development of enterprises.

\section{Improve the specific strategy of information disclosure of internal control defects of listed companies}

\subsection{Formulating comprehensive and reasonable certification standards}

As China's research on the disclosure of internal control defects of listed companies started late, it is now in the primary development stage, and its certification standards are not perfect. The emergence of this status quo will lead to the formalization of information disclosure of internal control defects of listed companies, and thus cannot be truly resolved. In this regard, the listed company must disclose the defect information according to the relevant requirements and format of the internal control evaluation report, fully disclose and display the real internal control defect 
information, and thus fundamentally improve the quality of the internal control defect information disclosure of the listed company, and use it. Reports more detailed internal control defect information. In addition, it is necessary to strengthen the supervision of the internal control system of listed companies, ensure the enthusiasm of listed companies for internal control defect information disclosure, and comprehensively improve the internal control level of listed companies.

\subsection{Realizing the independence of the board of directors and the audit committee}

With the continuous development of listed companies, the independent directors of the audit committee have been increasing, and it is in this case that it is easier to carry out internal control defect information disclosure. This is because most of the independent directors have a certain financial knowledge, which can effectively reduce the incidence of internal control defect accidents [7]. The audit committee has important significance in the internal control of defect information disclosure. If the internal audit institution of a listed company cannot achieve independence, it will easily lead to the implementation of the internal control system is not in place and the implementation is weak. In this regard, when internal audit institutions carry out the identification and disclosure of internal control defect information, they need to improve the corresponding supervision and actively meet the effective needs of internal audit policies. Under the condition that the corporate governance structure is relatively perfect, through the inclusion of internal audit into the management scope of the audit supervision system, effective supervision of the information disclosure of internal control defects is realized.

\subsection{Establishing and improving the internal control defect information disclosure system}

In order to achieve sustainable development, listed companies must implement a comprehensive adjustment of the identification and disclosure methods of internal control defects, and then establish and improve the internal control defect information disclosure system to meet the development requirements of core, applicability and integrity. The relevant regulatory authorities shall increase the disciplinary efforts against violations that occur during the process of disclosure of internal control defects, achieve full constraints on the behavior of listed companies, and achieve a distinction between financial reports and non-financial reports. In addition, by starting from multiple levels and angles, we actively seek out speculative space for listed companies, and display internal control defect information in the form of non-financial statements to transfer investors' attention [8]. In order to identify defect standards from the business level, relevant stakeholders and regulatory units need to grasp the adverse effects of the company's development process in a timely manner and reduce the subjective operation of people.

\subsection{Strengthen supervision and pursue legal responsibility}

As far as the overall development of listed companies in China is concerned, there is a certain degree of difference in their development level. If only relying on the listed company to participate in the internal control defect information disclosure, it cannot effectively meet the realization of the target. This requires the government to strengthen the attention to disclosure of internal control defects, and actively create favorable conditions for improving the disclosure of internal control defects. At the same time, listed companies should follow the relevant development principles when carrying out internal control assessment and auditing activities, and form the awareness of self-participation in internal control defect information disclosure. The Supervisory Committee, the Board of Directors and the management personnel shall play the main role and investigate the main responsibility for the failure to disclose the information on major defects of internal control. 


\section{Conclusion}

In summary, through the disclosure of internal control defect information, the effective connection between listed companies and various stakeholders has been realized. Whether the internal control defect information disclosure work is timely and sufficient will directly determine the development status of listed companies. In the process of internal control defect information disclosure, certain problems will inevitably be encountered. Enterprises and governments need to cooperate and formulate effective measures to solve them. Enterprises improve their internal status by improving their awareness of information disclosure of internal control defects. It is also necessary to introduce corresponding and targeted measures to achieve sustainable development of listed companies with joint efforts.

\section{References}

[1] Zhang Chao, Liu Xing. Information Disclosure of Internal Control Defects and Enterprise Investment Efficiency_Based on Empirical Research of Chinese Listed Companies. Nankai management review, Vol. 5 (2015) No.18, p. 136-150.

[2] Feng Zuni. Research on the status quo and problems of internal control information disclosure of listed companies in China. Southwestern University of Finance and Economics, Vol. 9 (2013) No.28, p. 148-151.

[3] Deng Shuo. Current Situation and Countermeasures of Internal Control Information Disclosure of Listed Companies. Business, Vol. 5 (2014) No.29, p. 88-89.

[4] Yan Zhe. Research on the Internal Control Information Disclosure of Listed Companies and Countermeasures. Business, Vol. 3 (2016) No.15, p. 16-17.

[5] Hao Wenkai. Research on the Status Quo and Countermeasures of Internal Control Information Disclosure of Listed Companies. China Securities and Futures, Vol. 5 (2013) No.3, p. 27-27.

[6] Hu Ruiying. The Influence of Internal Control of Listed Companies on the Quality of Accounting Information Disclosure and Countermeasures. China Business Review, Vol. 2 (2017) No.30, p. 127-128.

[7] Ni Lan, Zhang Jing. Research on Internal Control Information Disclosure of Listed Companies and Countermeasures. Business, Vol. 12 (2017) No.19, p. 35-39.

[8] Xu Yao. Status Quo and Countermeasures of Internal Control Information Disclosure of Listed Companies_- Taking Listed Companies in Jiangsu Province as an Example. Journal of Jinling Institute of Technology (Social Science Edition), Vol.3 (2017) No.15, p. 32-35. 